\title{
Research on University Computer Foundation Teaching based on Computational Thinking
}

\author{
Jian-Yan Zhang ${ }^{1, a}$, Jun-She Wang ${ }^{1, b}$ \\ ${ }^{1}$ School of Information Science and Engineering, Hebei University of Science and Technology \\ Shijiazhuang 050000, China \\ azjy@hebust.edu.cn, bwangjunshe@hebust.edu.cn
}

Keywords: computational thinking, university computer foundation, curriculum system

\begin{abstract}
As the rapid development of information society, people daily work and study rely on computer network as a platform environments, only familiar with computer operation skills which is not competent to meet the needs of the community, computational thinking ability and innovative consciousness are essential procedure for people to learn. Computer foundation course is not only playing an important role in undergraduate general education but also guiding the students to develop their computational thinking. The paper analyses some problems existed in computer foundation teaching and proposes a new computer foundation teaching mode based on computational thinking. From aspects of curriculum system, teaching method and so on, the paper discusses some strategies in developing computational thinking. The practice showed that the new teaching mode is useful to develop students self-learning ability, innovation ability and the ability to analyze and solve problems.
\end{abstract}

\section{Introduction}

It is an important link that develops students' comprehensive quality and innovation ability regarding university computer foundation function, which is also an important part of cultivating innovative talents in the information age[1]. With the improvement of society as a whole level of computer applications, new requirements is put forward as to teaching content University Computer Basic Course, which can not just focus on the use of software tools, and should be relatively stable, reflecting the core computer science ideas and methods training, much more prominent ways of thinking.

\section{Problems and Analysis of University Computer Teaching}

At present, basic computer courses role is insufficient understanding in many colleges and universities, teaching curriculum planning and execution are a mere formality, either teaching abstract theory computer, or talking about the application of simple operation is carried out in the class, universal problems are as follow.

Shallow of Course Understanding. A few computer operating systems, basic software operations, knowledge of hardware applications are major introduction during basic computer teaching course in the past. As China's information technology education in primary and secondary schools growing popularity, meanwhile the PC has entered every household, popularity of smart phones, etc., since it has been very easy for college students to master basic computer operations, some schools believe that this course dispensable for college students, Many people even mistakenly believe that "a PC that is designed for program", "Computer Basics course is only tool used for explain", and so a number of one-sided point of view[2]. Failure to recognize the basic ideas and important method of computer science which is essential for analyzing and solving the problem areas of expertise. A fact that it is important for undergraduates to possess computing technology and computing literacy under teaching lay a good foundation to solve the related professional area problems using computing technology.

Obsolete Teaching Content. Since computers technology develops very quickly, so that teaching content can not be updated in time. Currently teaching content focus on teaching students how to use 
computers, students can operate computer software only from imitative purpose, it is not useful to help students cultivate computational thinking, the profession of innovative research with computing method will be inhibited, students lose interest in basic computer courses easily and aim of learning computer is just for the final exam, it is difficult to achieve the improved computer application ability. If teachers can not guide students to have computer consciousness, thus students do not know how to use the computer effectively.

Inappropriate Teaching Methods. The complex theory, abstract code, interactive interface HMI, and application software design is included in the University Computer Basic Course contents, individual part has completely different key point compared to previous learning knowledge. If inappropriate teaching methods is adopted, it will make the teaching process to be extraordinarily complex, not only do students learn computer knowledge, but also the learning interest run out soon follows, especially for those students who have non-computer professional[3].

The reason is that, the students' thinking, awareness, discovery and problem solving capacity development and training is neglected in the teaching of computer basis. Therefore, it is urgent to explore computational thinking training ways and show the unique thinking charm to students in basic computer education actively, it is basic research key point to integrate Calculation methods and computational thinking ability in classroom teaching. Teaching Reform of teaching should be intensive enforcement about basic computer courses at present.

\section{Research and Development of Computational Thinking}

In 2006, Carnegie Mellon University professor, Jeannette M. Wing gives the definition of the concept of computational thinking in 《Communications of the ACM》magazine. Professor Zhou believes that computational thinking is the way to solve problem, design system and understand human behavior etc, which cover breadth of computer science thinking activity [4-5].

After that, the US National Science Foundation launched a basic research program for the computer science educational problems in 2007-"Education Promotion of university computing Way" (Pathways to Revitalized Undergraduate Computing Education, CPATH), the purpose to strengthen education reform efforts in American Universities and confirm clearly "computational thinking" as the core computing education reform in American University.

At present, more than 70 US universities involved in the program. The first "C9 League (C9) Computer Basic Course Seminar" held in Xi'an Jiaotong University by nine national "985 Project" construction of universities in July 2010, a joint statement was issued after the meeting. Core elements of the declaration mentions Computer basic teaching must be placed in important position, taking "computational thinking" ability training as computer teaching core task, thereby a more comprehensive teaching system and computer courses content will be established. Further a benchmark should be set up in nationwide colleges and universities along with computer-based teaching reform.

\section{Computer Basic Teaching Reform Measures based on Computational Thinking}

The Establishment of Stratified Computer Teaching Course System based on Computational Thinking. In order to meet the requirements of the social environment, the computational thinking oriented classification, University computer foundation courses tratification teaching reform, the basic teaching to highlight computational thinking ability training is proposed. We continue to strengthen the concept of computational thinking reform and experiment teaching ways to design practice teaching by cultivating innovative talents in the class. The new "University Computer Foundation" curriculum system shown in Figure 1, the system various branches integrated with computational thinking concepts. 


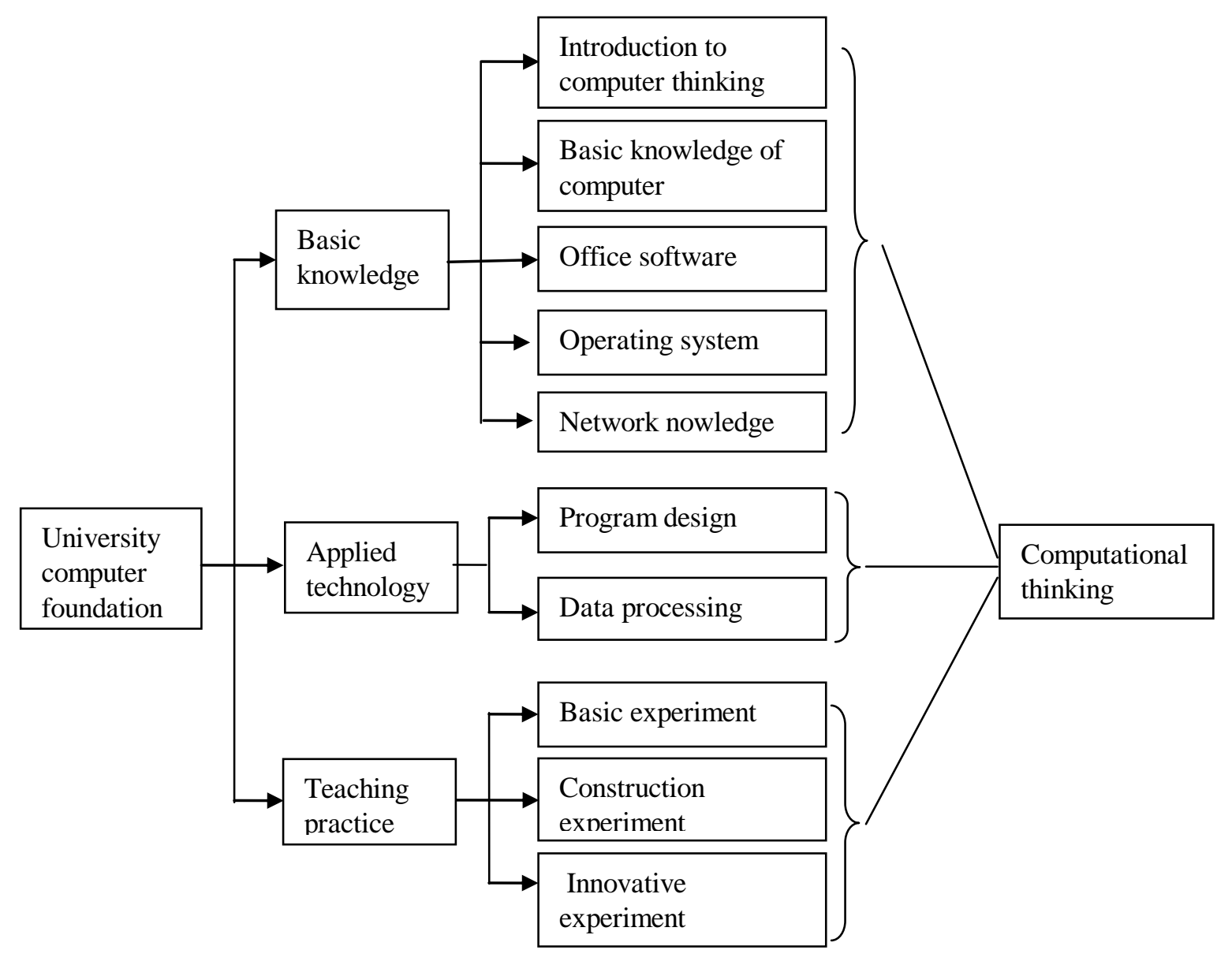

Fig.1 "University Computer Foundation" curriculum system

Focus on Theoretical Analysis and Cultivate Computer Thinking Conscious. In the theory class, the focus should be put on students' computer applications and computational thinking analysis as well as basic skills to solve practical problems. The previous indoctrination explanation and operation which should be updated to increased interaction. Not only pay attention to teaching basic theory, but also emphasize the process of training students to solve the problem in class, For example, take "how to use the ID card information to calculate the age of the subject" program as an example to introduce excel: Firstly, guide students to analyze data type and identify ID card information as text type data, and then the use of character functions which represent your date of birth Year of data, the next step to convert the year text data into numerical data. Finally, the actual age will be calculated by the program formula. Strengthening Practical Teaching to Enhance the Computational Thinking Ability. According to practice teaching requirement under the new curriculum system, the practice teaching should be developed with basic experiment, construction experiment and innovative experiment. Basic experiments are commonly used to help students to verify basic knowledge through specific operations. It increases the content of knowledge based thinking and helps the students understand computational thinking is the leading role in the experimental teaching. Construction experiment consciously train students to build a common mathematical model using abstract thinking and understand computational thinking approach to problems progress. Innovative experiments develop and enhance students' innovative consciousness and innovative abilities, not only reflect the various disciplines actual needs for computer technology, but also cover computational thinking ideas. Through personal involvement and student innovation to explore the expansion of consciousness in a wider range, meanwhile enhance hands-on skills and innovation.

Explore new Teaching Model to Improve Cognitive Abilities. Regarding basic computer teaching, it is not basic computer knowledge and software skills to teach, if so, boring course will discourage students' interest in computers and lead to rigid thinking, therefore, teaching mode should transfer to be 
flexible in the computer basic teaching, MOOC, flipped classroom, small papers, panel discussions and other learning teaching methods should be adopted, besides classroom lectures and hands-on. Practice proved that the new teaching model to mobilize the enthusiasm of students, improve students' self-learning ability, innovation ability and computational thinking.

Teaching Practice and Effect. "computational thinking Introduction" elective course is set up in all majors in autumn 2014, MOOC courses introduced into the engineering excellence classroom teaching from school online in autumn 2015, good teaching results are achieved by Computer Basic Course pilot teaching which is based on computational thinking teaching. The comparison results are shown in Table 1 which displays engineering excellence classes and regular classes final mark (out of 100) involved in the reform.

Table 1 Student Achievement Analysis

\begin{tabular}{|c|c|c|c|c|c|c|c|c|}
\hline category & Teaching mode & Total & Average & $\begin{array}{c}\text { Failed } \\
(\%)\end{array}$ & $\begin{array}{c}\text { Pass } \\
(\%)\end{array}$ & $\begin{array}{c}\text { Fair } \\
(\%)\end{array}$ & $\begin{array}{c}\text { Good } \\
(\%)\end{array}$ & $\begin{array}{c}\text { Excellent } \\
(\%)\end{array}$ \\
\hline $\begin{array}{c}\text { excellent } \\
\text { engineer class }\end{array}$ & new & 40 & 78.62 & 0 & 35 & 17.5 & 37.5 & 10 \\
\hline regular class & traditional & 122 & 65.48 & 18.03 & 35.26 & 22.13 & 18.85 & 5.73 \\
\hline
\end{tabular}

New teaching methods to improve students' initiative, self-learning ability and innovation, the concept of computational thinking will be deeper.

\section{Conclusion}

It is a long-term, complicated and important task to train computational thinking ability in basic computer teaching, the task can not be completed which merely rely on their own in a short time. Only the majority of basic computer education worker take computational thinking teaching actively and consciously to cultivate the student's computational thinking after reflection and exploration efforts. It will help students to lay a good foundation for solving practical problems and further enhancing students' learning potential, innovative ability ,once computational thinking deeply root in students.

\section{Acknowledgment}

This work is supported by the Higher Education Teaching Reform Project in Hebei Province (Training system of practical ability for information talents), and the Reform Pilot Project of Innovative Talents Training Mode of Hebei University of Science and Technology.

\section{References}

[1]G. Liu, M. Li. Thoughts on the reform of university computer series courses [J]. China University Teaching, 2012 (11):39-41.

[2]X. Zhang, F. Chen, R. Li, and G. Li. "Teaching reform of university computer foundation courses under 'One Body, Two Wings' talent training mode" [J], Experrimental Technology and Management, 2013,30(11):199-202

[3] Q.Mou. The Pattern Research and Practice of Computer Basic Course Teaching and Learning Based on Computational Thinking [D]. Sichuan Normal University, 2012.

[4]Jeannette M. Wing. Computational Thinking [J]. Communications of the ACM, March 2006, 49(3):33-35.

[5]Z. Wang. Introduction to Computational Thinking [M]. Beijing: Higher Education Press, 2012. 